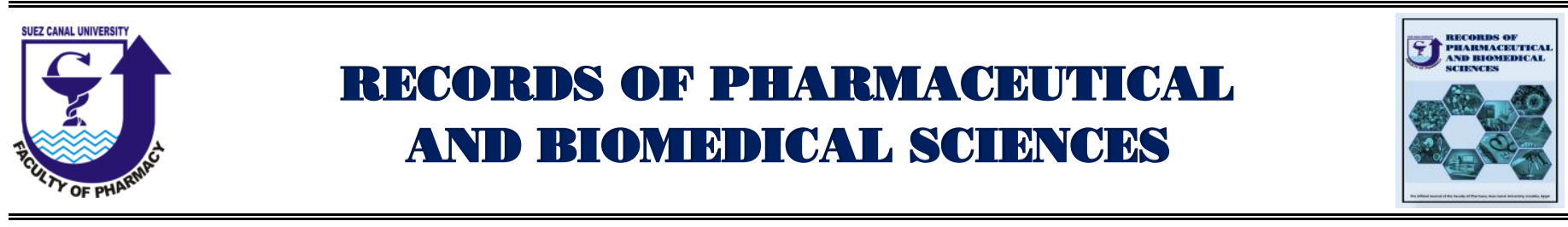

\title{
Antimicrobial activity of different extracts of Plicosepalus acacia
}

\section{Ghadeer El- Shafei ${ }^{a}$, Bodoor Al-Hazmi ${ }^{a}$, Afnan Marghelani ${ }^{a}$, Dania Al-Moalem ${ }^{\text {a }}$, Jihan M. Badr ${ }^{b^{*}}$, Nayera A. Moneib}

${ }^{a}$ Department of Natural Products and Alternative Medicine, Faculty of Pharmacy, King Abdulaziz University, Jeddah 21589, Saudi Arabia

${ }^{\mathrm{b}}$ Department of Pharmacognosy, Faculty of Pharmacy, Suez Canal University, Ismailia, 41522, Egypt

${ }^{\mathrm{c}}$ Department of Micobiology and Immunology, Faculty of Pharmacy, Cairo University, Cairo, 11562, Egypt

Received on: 29.11 .2016

Revised on: $\quad 12.01 .2017$

Accepted on: 20.01.2017

\section{Keywords}

Plicosepalus acacia

Loranthaceae

Antimicrobial activity

\begin{abstract}
The antimicrobial activity of different extracts of Plicosepalus acacia was tested against a number of microorganisms using agar diffusion method. The microorganisms used are Staphylococcus aureus, Bacillus subtilis, Escherichia coli, Pseudomonas aeruginosa and Candida albicans. Ethyl acetate extract exhibited the highest activity against the tested Gram-positive bacteria (inhibition zones ranged from $24-25 \mathrm{~mm}$ ) and also towards the fungus Candida albicans (25 mm inhibition zone). All the tested extracts were highly effective against the well-known highly resistant Gram-negative bacteria Pseudomonus aeruginosa, while the highest activity was observed with the chloroform extract (37 $\mathrm{mm})$.
\end{abstract}

\section{Introduction}

Folk medicine is the method by which human beings have been trying to eliminate pain and promote good health since the beginning of time. Many of the methods used in folk medicine are ones that have been passed down from generation to generation.

\footnotetext{
*Corresponding author

Business Tel: +20-01091332451

Fax: $\quad+20-64-3561877$

E-mail: gihan96@hotmail.com
}

Mistletoe is the common name for obligate hemiparasitic plants in several families in the order Santalales (Vaknin et al., 1996). These plants grow attached to and penetrating within the branches of a tree or shrub by a structure called the haustorium, through which they absorb nutrients from the host plant. Among the mistletoe are those belonging to family Loranthaceae; a family of flowering plants consisting of about 75 genera and 1,000 species of woody plants. Plants belonging to family 
Loranthaceae have been traditionally used in folk medicine to treat various diseases as smallpox, diarrhea and hookworms infections (MorenoSalazara et al., 2008). Mistletoe plants attached to lime trees have been also reported to be used as medicinal herbs for treatment of tonsilitis and otitis media (Osadebe et al., 2004). Previous studies on those genera have also focused on its antidiabetic (Obatomi et al., 1994; Osadebe et al., 2010), cholinomimetric, vascular and potential antitumor and anticancer activities (Sadika et al., 2003).

Our survey studies illustrated that Plicosepalus acacia is widely used in Saudi Arabia for treatment of various diseases as diabetes mellitus, cancer, bronchitis, tonsillitis and common cold. A previous work on this plant revealed that it contains a number of phenolic compounds where most of them possess antimicrobial activity (Badr et al., 2013). This work aims to investigate different plant extracts in order to determine the most active one in an initial step for its use as a drug lead.

\section{Materials and methods}

\subsection{Plant collection and preparation of extracts}

Plicosepalus acacia was collected from Alola at the North of the Kingdom during 2010. The collected plant was identified by Dr. Nahed Morad, Assistant Professor, Faculty of Science, King Abdulaziz University. A voucher sample (2010-PA1) was kept at Natural Products Department, Faculty of Pharmacy, King Abdulaziz University, Saudi Arabia. The plant was air-dried, finely powdered ( $2 \mathrm{~kg}$ of the dry plant), then extracted. The cold maceration technique was used for extraction of the plant. The powdered plant was soaked in ethyl alcohol at room temperature. After seven days, the extract was filtered. The residue was again dipped in ethyl alcohol for additional seven days and filtered thereafter. The filtrate was combined and ethanol was evaporated under vacuum, using a rotary evaporator to yield viscous greenish-brown colored extract $(8$ $\mathrm{gm})$.

\subsection{Fractionation}

Distilled water was added to a portion of the ethanol extract $(7 \mathrm{gm})$ in a ratio of $2: 1$, followed by successive fractionation with hexane $(3 \times 500 \mathrm{ml})$, chloroform ( $3 \times 500 \mathrm{ml})$ and ethyl acetate $(3 \times 500$ $\mathrm{ml})$. Each extract was concentrated separately using vacuum rotary evaporator and stored at $4{ }^{0} \mathrm{C}$ till use.

\subsection{Microorganisms}

The antimicrobial activity of plant extracts was determined against Gram positive bacteria (Staphylococcus aureus ATCC 6538, Bacillus subtilis ATCC CC33), Gram negative bacteria (Escherichia coli ATCC 5087, and Pseudomonas aeruginosa ATCC 9027) and yeast (Candida albicans ATCC 60193).

\subsection{Screening of the antimicrobial activities using the disk diffusion technique}

The antimicrobial activity spectra were determined using the agar cup diffusion method (Koneman et al., 2006). Adjusted inoculums $(0.1 \mathrm{ml})$ of each microorganism, equivalent to the turbidity of 0.5 McFarland standards, were aseptically inoculated into $20 \mathrm{ml}$ molten Muller Hinton agar and poured into sterile petri dishes until hardened. A sterile cork borer 


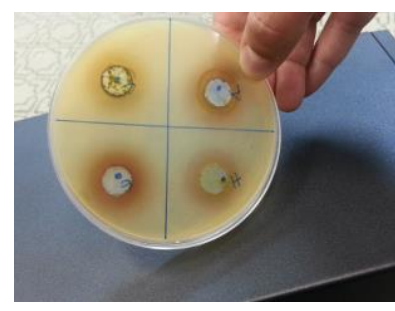

1

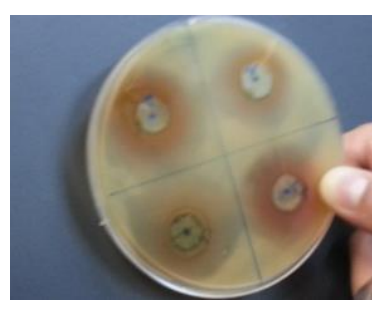

2

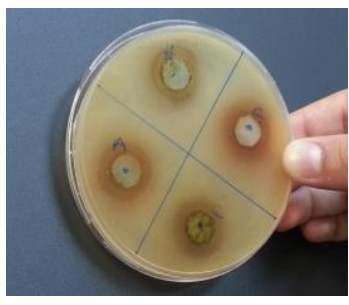

3

Figure 1: Inhibition zones of the four extracts of Plicosepalus acacia against $E$. coli (1), P. aeruginosa (2) and B. subitilis (3).

was used to prepare four cups of $6 \mathrm{~mm}$ diameter in the agar medium. Accurately measured $(0.03 \mathrm{ml}$; initially prepared as $1 \mathrm{mg} / \mathrm{ml}$ ) solution of each extract (ethanol, chloroform and ethyl acetate) was added to the cups with a micropipette.

The plates were incubated at $37^{\circ} \mathrm{C}$ for 24 hours. Control cups impregnated with dimethylsulfoxide were used to determine the solvent activity. Cups filled with gentamycin and ciprofloxacin were used as antibacterial standard, while amphotericin B was used as an antifungal standard (each of the used references was prepared in a concentration of 0.01 $\mathrm{mg} / \mathrm{ml}$ ). Activity of each extract was determined by measuring the diameter of the inhibition zone in $\mathrm{mm}$. The technique was performed in duplicate and the mean diameter of each inhibition zone was recorded.

\section{Results and discussion}

The treatment of infectious diseases with antimicrobial agents continues to present problems in modern day medicine with many studies showing a significant increase in the incidence of side effects and the resistance that pathogenic microorganisms build against several antibiotics (Alanis, 2005). Thus, from the past few decades, research has been directed towards analyzing medicinal plants, as potential crude drugs as well as a source for natural compounds that act as new anti-infection agents (Powers, 2004; Nascimento et al., 2000). In this study, as indicated from Figure 1 and Table 1, the four extracts of Plicosepalus acacia showed significant antibacterial activity against all the tested Gram-positive (Staphylococcus aureus and Bacillus subitilis) and Gram-negative bacteria (Escherichia coli and Pseudomonus aeruginosa). Ethyl acetate extract exhibited the highest activity against the tested Gram-

Table 1: Antimicrobial activity of different extracts of Plicosepalus acacia as measured by zones of inhibition in $\mathbf{m m}$.

Tested extracts and antibiotics

\begin{tabular}{cccccccc} 
Organism & Hexane & Chloroform & Ethyl acetate & Ethyl alcohol & Ciprofloxacin & Gentamycin & Amphotercin B \\
\hline S. aureus & 22 & 19 & 24 & 21 & 37 & 26.5 & - \\
B. subitilis & 20 & 20 & 25 & 20 & 30 & 40.5 & - \\
E .coli & 22 & 21 & 20 & 23 & 43.5 & 29.5 & - \\
$\boldsymbol{P}$. aeruginosa & 30 & 37 & 35 & 33 & 37.5 & - & - \\
C. albicans & 20 & 20 & 25 & 22 & & 22 \\
\hline
\end{tabular}


positive bacteria showing inhibition zones 24 and 25 $\mathrm{mm}$ against Staphylococcus aureus and Bacillus subitilis respectively. This activity corresponds to more than half the strength exhibited by the reference antibiotics, ciprofloxacin and gentamycin. Surprisingly, all the tested extracts were highly effective, as compared to the reference antibiotic, against the well known highly resistant Gramnegative bacteria Pseudomonus aeruginosa. The highest activity was observed with the chloroform extract showing an inhibition zone of $37 \mathrm{~mm}$. Ethyl alcohol extract revealed the highest activity against $E$. coli (23 mm inhibition zone). Finally, C. albicans showed the highest susceptibility towards ethyl acetate extract (25 mm inhibition zone).

From the above result, we can conclude that the ethyl acetate extract possesses the most significant antimicrobial activity; this could be attributed to its chemical constituents. As in a previous study, it was illustrated that the ethyl acetate extract of this plant accumulates a number of phenolic compounds including rutin, quercetin, catechin, gallic acid, methyl gallate and loranthin (which is composed of two units; a coumarinand catechin (Badr et al., 2013). Since it is well known that many of the phenolic compounds possess antimicrobial activity; this can justify the high antimicrobial activity of the ethyl acetate extract.

The tested microorganisms (S. aureus, E.coli and $P$. aeruginosa) are common causes of hospital acquired infections and are responsible for illnesses ranging from minor skin infections, to life-threatening diseases (Gaynes and Edwards, 2005; Fridkin, 2001). Additionally, reasonable antifungal activity against
Candida albicans was detected by all extracts.

These results highlight the effective extracts that could be used for eradication of the corresponding tested microorganisms.

\section{Conclusion}

It could be concluded from the obtained data to consider this plant; Plicosepalus acacia as a potential source in the development of new antimicrobial drug for the treatment of infectious diseases. However, more studies need to be conducted using wider range of microorganisms. Also, in -vivo toxicity tests of the effective extracts should be performed.

\section{Conflict of interest}

The authors report no declaration of conflict of interest.

\section{Acknowledgements}

No acknowledgement.

\section{References}

Alanis, A.J., 2005. Resistance to antibiotics: Are we in the post-antibiotic era ? Arch. Med. Res.. 36, 697705.

Badr, J.M., Shaala, L.A., Youssef, D.T., 2013. Loranthin: A new polyhydroxylated flavanocoumarin from Plicosepalus acacia with significant free radical scavenging and antimicrobial activity. Phytochem. Lett. 6, 113-117.

Fridkin, S.K., Edwards, J.R., Tenover, F.C., Gaynes, R.P., McGowan, J.E., 2001. Antimicrobial resistance prevalence rates in hospital antibiograms reflect prevalence rates among pathogens associated with hospital-acquired infections. Clin. Infect. Dis. 33, 324-330.

Gaynes, R., Edwards, J.R., 2005. Overview of 
nosocomial infections caused by gram-negative bacilli. Clin. Infect. Dis. 41, 848-854.

Koneman, E.W., Allen, S.D., Janda, W.M., Paul, C.S., Winn, W.C., 2006. Antimicrobial susceptibility testing. In: Color atlas and textbook of diagnostic microbiology. 7th edition. J.B. Lippincott Co., Philadelphia. Ch.17, 945-1022.

Moreno-Salazara, S.F., Robles-Zepedab, R.E., Johnsona, D.E., 2008. Plant folk medicines for gastrointestinal disorders among the main tribes of Sonora, Mexico. Fitoterapia. 79, 132-141.

Nascimento, G.F., Locatelli, J., Freitas, P.C., Silva, G.L., 2000. Antibacterial activity of plant extracts and phytochemicals on antibiotic resistant bacteria. Braz. J. Microbiol. 31, 247-256.

Obatomi, D.K., Bikomo, E.O., Temple, V.J., 1994. Anti-diabetic properties of the African mistletoe in streptozotocin-induced diabetic rats. J. Ethnopharmacol. 43, 13-17.

Osadebe, P.O., Okide, G.B., Akabogu, I.C., 2004.
Study on anti-diabetic activities of crude methanolic extracts of Loranthus micranthus (Linn.) sourced from five different host trees. J. Ethnopharmacol. 95, 133-138.

Osadebe, P.O., Omejea, E.O., Nworub, S.C., Esimonec, C.O., Uzora, P.F., Davida, E.K., Uzoma, J.U., 2010. Antidiabetic principles of Loranthus micranthus Linn. parasitic on Persea americana. Asian Pac. J. Trop. Med. 3, 619-623.

Powers, J.H., 2004. Antimicrobial drug developmentthe past, the present and the future. Clin. Microbiol. Infect. 4, 23-31.

Sadika, G., Islama, R., Rahmanb, M.M., Khondkara, P., Rashidc, M.A., Sarker, S.D., 2003. Antimicrobial and cytotoxic constituents of Loranthus globosus. Fitoterapia 74, 308-311.

Vaknin, Y., Yoram, Y., Eisikowitch, T.D., 1996. Flowering seasonality and flower characteristics of Loranthus acaciae Zucc. (Loranthaceae): implications for ad-vertisement and bird-pollination. Sex. Plant Reprod. 9, 279-285. 